\title{
A Study of Current and Desired State of Physics Education in Iranian Female Secondary Schools
}

\author{
Mohammad J. Liaghatdar \\ School of Education, University of Isfahan \\ PO box 81746 73441, Isfahan, Azadi Square, University of Isfahan, Iran \\ Tel: 98-311-793-2536Ｅ-mail: javad@edu.ui.ac.ir
}

Asghar Soltani

Faculty of Literature and Humanities, School of Education, Shahid Bahonar University of Kerman, PO box 76169133, Shahid Bahonar, University of Kerman, Afzalipour Square, Kerman, Iran

Tel: 98-913-209-3549 E-mail: a.soltani.edu@uk.ac.ir

Rashin Shojaei (Corresponding Author)

M.A. of Educational Planning, Department of Education, Khorasgan (Isfahan) branch,

Islamic Azad University, Isfahan, Iran

Tel: 98-913-229-5530Ｅ-mail: rashin.shojaei@gmail.com

Ali Siadat

School of Education, University of Isfahan

PO box 8174673441 -, Isfahan, Azadi square, University of Isfahan, Iran

Tel: 98-311-793-5420 E-mail: s.a.siadat@edu.ui.ac.ir

Received: September 22, 2011 Accepted: September 26, 2011 Published: February 1, 2012

doi:10.5539/ies.v5n1p50

URL: http://dx.doi.org/10.5539/ies.v5n1p50

\begin{abstract}
This study has examined the characteristics of physics teachers, their professional competences, supplies of equipments and technologies, appropriate textbooks and motivational factors in students' learning of physics from female physics teacher's points of view. The population included all female physics teachers in Isfahan city and a total of 88 teachers were selected as sample of study. The study was a descriptive survey that used researcher made questionnaire consists of 46 items. Cronbach's alpha coefficient for this scale was set to be .95 . For data analysis, descriptive statistics, t-tests and ANOVA test were used. The results showed that in the present state, physics teachers have a low level of scientific knowledge. In terms of professional skills, their abilities were average and educational equipments and technologies were available at low level. Moreover the satisfaction of female physics teachers of books and educational texts was moderate. Meanwhile, the motivation for learning the lessons of physics was moderate. Also the results in desired state showed that all components of study could be effective in learning physics. Accordingly, it is recommended to enhance learning and teaching physics education, school should be equipped to supplies and technologies for teaching physics, including virtual laboratory.
\end{abstract}

Keywords: Education, Science education, Physics education, Current state, Desired state, Secondary education

\section{Introduction}

Science education is an important part of educational activities in schools. Due to the nature of science education it has very large differences with the other domains of human knowledge. Therefore requires the use of appropriate techniques in their learning and teaching processes (Soltani, 2004). Science education experts consider three following objectives for teaching science in different disciplines and different levels:

- Knowledge Transferring: The courses consist of a series of principles, rules and regulations that constitute the 
basic knowledge of science.

- Creating and developing the necessary skills like as: 1- Observation; 2- Measuring; 3- Data collection 4Interpretation of results; 5- Hypothesizing; 6- Provision; 7- Application of Tools; 8- contact; 9- designing of research.

- $\quad$ Creating and developing the necessary attitudes. (Ahmadi, 2006).

The objectives of physics education are classified knowledge, skills, and attitudes.

1- Objectives of Knowledge: knowledge about the concepts, laws and theories of science is necessary to learn skills and increasing knowledge. These objectives include:

Knowledge: 1- Familiarity with definitions, terms , symbols, concepts, laws and theories 2- Familiarity with physical relationships and their analysis 3 - using the theory and laws to explain physical phenomena;

\section{2- Objectives of Skills:}

A: Mental skills: 1 - the ability to design and conclusion of carried out experiments 2 - the ability to Hypothesizing 3 - the ability to predict events based on the experiences;

B: Practical skills:

1 - The ability to doing some experiments and physical data collection and analysis of them 2 - the ability to measuring and calculating some quantities 3 - the ability to build some tools for doing physics experiments.

3- Objectives of Attitude: 1- Understand the importance and role of physics in understanding the greatness of creation; 2- Strengthening the sense of curiosity about physical phenomena. 3- Create and reinforce scientific thinking and a sense probe to explore the causal relationship between the physical phenomena; 4-Reinforce the critical view of physical theories (Motamedi, 2007).

The findings of the Third International Mathematics and Science Study in 2003 in Iran and many developing countries demonstrated very poor results in all tests of Iranian students. This shows that the quality of science education in Iran is lower than international standards (KiaManesh, and Khalkhali, 2002). According the results of a study that has conducted on learning difficulties of high school students in physics, the problems primarily related to the teacher, and how teachers are trained (Abbaszadeh, 2003).

Accordingly, the research questions of this study are:

i. To what extent physics teachers are mastered in contents of physics books and knowledge of physics?

ii. To what extent physics teachers have professional skills and competencies in physics teaching? (Teaching methods, evaluation methods, instructional design...)

iii. To what extent physics teachers have necessary equipment and technologies? (Physics lab, computer lab, overhead, PowerPoint, etc.)

iv. To what extent physics education has appropriate texts and educational content?

v. To what extent students have motivational factors to enjoy learning physics?

vi. Is there any difference between current and desired state in each component?

\section{Research Background}

Neber et al. (2008) in their research on Chinese high-school students self regulated learners in physics classroom investigated 4 questions:

i. Can students who are attending a regular high-school be considered as self-regulated physics learners?

ii. Does the extent of self-regulated learning in physics vary with the grade level of these students, and are students attending higher grades more self-regulated in learning physics?

iii. Does self-regulated learning vary with gender, and can girls be considered as either more or as less self-regulated learners in physics than boys?

iv. Does self-regulated learning vary with gender, and can girls be considered as either more or as less self-regulated learners in physics than boys?

The results showed that in summary some components of self-regulated learning vary with the grade-level of the students which provides a positive answer to the first part of the second research question. However, most of these variations do not confirm the expectation of stronger psychological components for self-regulated learning in physics with 10th graders. 
Rezaei and Katz (2002), investigated using computer assisted instruction to compare the inventive model and the radical constructivist approach to teaching physics. They introduced a new way of evaluating instructional strategies by using computers. The results showed that only the Inventive Model lead to coherent conceptual learning. It was concluded that the process of conceptual change is gradual and continuous.

Kopenen, I. T. and Mantyla, T. (2006), investigated generative role of experiments in physics and in teaching physics. They propose a reconstruction, which is based on the idea that in epistemology of experiments the inductive like generative justification of knowledge is central. In their opinion A generative view makes it possible to retain those aspects of experiments which make them purposeful for learning and can give a starting point for students' own construction of knowledge. The reconstruction also helps to conceive the experiments with their correct historical role and helps to bring back the generative use of experiments in teaching, which, after all, has never vanished from the practice of physics.

Ding, and Harskamp (2006), explored the influence of partner gender on female students' learning achievement, interaction and the problem-solving process during cooperative learning. They also explored the differences between female and male communication styles, and content among the three research groups. It showed that the females' interaction content and problem-solving processes were more sensitive to partner gender than were those for males. This might explain why mixed-gender cooperation in physics disadvantages females in high schools.

Seroglou and Koumaras (2001), focused on the selection, classification and comparative presentation of the various proposals concerning the contribution of the history of physics in physics education, that have been designed and/or carried out as part of either research or curriculum development during the last century. They considered three dimensions of physics education:

1- The cognitive dimension: The cognitive dimension includes the following categories: The teaching and learning of the content of physics, of the methodology of physics, of problem solving skills and students' alternative ideas. Each one of these categories reflects a cognitive objective of the teaching - learning of physics.

2- The metacognitive dimension: The metacognitive dimension includes the understanding of the nature of science and the understanding of the science-society interrelations which are both essential factors in the teaching and learning of physics.

3- The emotional dimension: The emotional dimension of the framework represents the attempts of researchers and curriculum designers in physics education to develop and apply (observable, measurable and improvable) methods in order to attract pupils to the world of physics. Efforts in this field vary from the awakening of pupils' interest, to their motivation, to the study of attitudes and finally to the study of behavioral intention.

Krusberg (2007), explored three emerging technologies in physics education. The technologies-Physlet Physics, the Andes Intelligent Tutoring System (ITS), and Microcomputer-Based Laboratory (MBL) Tools-assessed particularly in terms of their potential at promoting conceptual change, developing expert-like problem- solving skills, and achieving the goals of the traditional physics laboratory.

Zavala and Alarcon (2007), in their research on innovative training of in-service teachers for active learning, described a short development course for in-service physics teachers. The activities were structured as follows:

- Discussion in the small tutorial group

- General discussion

- Reading physics education research literature

- Closure by an instructor

Afra et al. (2009) in their research on inquiry-based teaching strategies in physics education investigated the alternative conceptions that a group of 12 Lebanese students in a grade 9 class hold about electricity. They also attempted to evaluate learning outcomes of implementing in that class an inquiry-based module for the acquisition of conceptual understanding of basic concepts in electricity. Fourteen mostly subjective tests were administered hroughout the implementation phase of the inquiry-based module to assess the evolution of participants conceptions. Results of their study showed that the implemented inquiry-based approach was successful in enhancing participants_conceptual understanding of the targeted DC circuit concepts.

Hubbard and Abell (2005), on their research on comparing the beliefs of pre-service elementary teachers with and without an inquiry-based physics course examined the beliefs about science teaching and learning held by elementary pre-service teachers in a science methods course, comparing students who had experienced an inquiry-based physics course with those who had not. Results showed that students with no experience in the inquiry-based physics course maintained their limited view that science teaching should be "fun," with the teacher 
as teller and fun-maker.

Mantyla (2011), mentioned that in physics teacher education, two central goals are first to learn the structures of physics knowledge, and second the processes of its construction. To know the structure is to know the framework of concepts and laws; to know the processes is to know where the knowledge comes from, how the framework is constructed, and how it can be justified. The results of their research showed that the didactical reconstruction of processes helps students in arguing how to form the electromagnetic induction law and that the experiments and models have a distinct role in supporting students' knowledge claims.

\section{Method}

The study was a descriptive survey that used researcher made questionnaire consists of 46 items for data collecting. After pilot study on 30 physics teacher, the Cronbach's alpha coefficient for this scale was set to be .95 . The population of study consists of all female high school physics teachers in five educational areas of Isfahan city that were 163 teachers. The sample of study was 88 secondary female physics teachers. For data analysis, descriptive statistics, t-tests and ANOVA test were used.

\section{Results}

The first research question: To what extent physics teachers are mastered in contents of physics books and knowledge of physics?

Table 1 shows that in current state, observed $t$ at the level of $\mathrm{P} \leq 0.05$ is statistically significant. It means that in current state, physics teachers are mastered in contents of physics books and knowledge of physics in a low level. The results of table 1 shows also shows that in desired state, observed $t$ at the level of $P \leq 0.05$ is statistically significant. In other words it means that physics teachers should be mastered in content of physics books and knowledge of physics in desired state.

The second research question: To what extent physics teachers have professional skills and competencies in physics teaching? (Teaching methods, evaluation methods, instructional design ...)

As is observed in Table 2, observed $t$ at the level of $\mathrm{P} \leq 0.05$ is not statistically significant. In other words, in current state, however have some professional skills and capabilities but it is not appropriate. Also in the desired state the result of table 2 shows that observed $t$ at the level of $\mathrm{P} \leq 0.05$ is statistically significant. Therefore should have high level of professional skills and capabilities.

The third research question: To what extent physics teachers have necessary equipment and technologies? (Physics lab, computer lab, overhead, PowerPoint, etc.)

Table 3 shows that in current state, observed $t$ at the level of $P \leq 0.05$ is statistically significant. It means that in current state, the teachers rarely technologies and equipment in physics education. The results of table 3 also show that in desired state, observed $t$ at the level of $\mathrm{P} \leq 0.05$ is statistically significant. It means that physics teachers should use technologies and equipment in physics education.

Fourth research question: To what extent physics education has appropriate texts and educational content?

According to the results of table 4 shows that in current state, observed $t$ at the level of $\mathrm{P} \leq 0.05$ is statistically significant. It means that in current state, physics books and educational contents of physics are appropriate. The results of table 4 shows also shows that in desired state, observed $t$ at the level of $\mathrm{P} \leq 0.05$ is statistically significant. In other words it means that physics books and educational contents of physics should be in high level of quality.

The fifth research question: To what extent students have motivational factors to enjoy learning physics?

As is observed in Table 5, observed $t$ at the level of $\mathrm{P} \leq 0.05$ is statistically significant. It means that in current state, teachers using of motivational factors for physics learning is moderate. The results of table 5 also show that in desired state, observed $t$ at the level of $\mathrm{P} \leq 0.05$ is statistically significant. In other words, teachers should use the motivational factors for learning physics.

The sixth question: Is there any difference between current and desired state in each component?

According the results of paired t-test, observed difference between current and desired state in each component of study is meaningful at the level of $\mathrm{P} \leq 0.05$. Among them, the greatest difference is between current and desired state of third components (technologies and equipment in physics education). Furthermore the minimum difference is observed between the current and desired state of second components (motivational factors for learning physics).

\section{Conclusions}

In this study to assess the present and desired state of physics learning, to evaluate the proficiency and skills physics 
teachers, the availability and features of the high schools IT equipment and technologies in physics teaching and the status of motivational factors and learners interests in physics learning were discussed. This study, according to previous research in this area and investigated the current and desired state of physics education by using a researcher made questionnaire. The following table summarizes the results of the study.

According to table 7, in current state, "motivational factors for learning physics" has the highest average (M=3.27) and "equipment and technologies in physics teaching" has the lowest average. It is may be due to that motivational factors are internal factors that drive students to learning physics automatically. Also various reasons such as lack of credibility could be cause of deficiency of educational equipment and technologies in physics education.

In desired state, "motivational factors for learning physics" has the highest average $(\mathrm{M}=4.52)$ and "mastery in content of physics books and knowledge of physics" has the lowest average $(\mathrm{M}=4.20)$. It is may be due to mastery of physics teachers on knowledge of physics and physics text.

According to results of study, the greatest difference is between current and desired state of third components (technologies and equipment in physics education). Furthermore the minimum difference is observed between the current and desired state of second components (motivational factors for learning physics). Therefore it is recommended to reduce this gap, improve motivational factors between students and increase technologies and equipment to teach physics in virtual environment. It is recommended to enhance the education level of physics teachers, physics professors used to train them in in-service programs. Also it is recommended to enhance professional skills and capabilities of physics teachers.

\section{References}

Abbas Zadeh, M. (2005). A Study of the problems of teaching and learning in physics. Iranian Journal of Physics Education, Vol 20, No. 3 .

Afra, N. C., Osta, I., \& Zoubeir, W. (2009). Students' alternative Conceptions about electricity and effect of inquiry-based teaching strategies. International Journal of Science and Mathematics Education, 7, 103-132

Ahmadi, Ahmad. (2005). necessity of the field of physics education. Iranian Journal of Physics Education, Vol. 2, No. 7.

Ding, N., \& Harskamp, E. (2006). How partner gender Influences female students' problem solving in physics education. Journal of Science Education and Technology, 15(5), 331-343. http://dx.doi.org/10.1007/s10956-006-9021-7

Hubbard, P., \& Abell, S. (2005). Setting sail or missing the boat: comparing the beliefs of preservice elementary teachers with and without an inquiry-based physics course. Journal of Science Teacher Education, 16, 5-25

Soltani, A. (2004). A feasibility study of establishing science education master courses in Iranian universities. Master thesis, University of Isfahan.

Khalkhali, M. (2002). Diagnostic of the curriculum and strategies for reform in Iran. Tehran: Sogand Publication.

Koponen, I. T., \& Mantyla, T. (2006). Generative role of experiments in physics and in teaching physics: A suggestion for epistemological reconstruction. Science \& Education, 15, 31-54. http://dx.doi.org/10.1007/s11191-005-3199-6

Krusberg, Z. A. C. (2007). Emerging technologies in physics education. J Sci Educ Technol, 16, 401-411. http://dx.doi.org/10.1007/s10956-007-9068-0

Matyla, T. (2001). Didactical reconstruction of processes in knowledge construction: pre-service physics teachers learning the law of electromagnetic induction. Research in Science Education, May 2011. http://dx.doi.org/10.1007/s11165-011-9217-6

Motamedi, E (2007). History of physics education in Iran (Secondary Education).Tehran: Lohzarrin publication.

Neber, H., He, J., LIU, B., \& Schofield, N. (2008). Chinese high-school students in physics classroom as active self-regulated learners: cognitive, motivational and environmental aspects. International Journal of Science and Mathematics Education, (2008) 6: 769-788

Rezaei, A. R., \& Katz, L. (2002). Using computer assisted instruction to compare the inventive model and the radical constructivist approach to teaching physics. Journal of Science Education and Technology, Vol. 11, No. 4,367-380. http://dx.doi.org/1059-0145/02/1200-0367/0

Seroglou, F., \& Koumaras, P. (2001). The contribution of the history of physics in physics education: A review. Science \& Education, 10, 153-172 
Zavala G., \& Alarcon, H. (2007). Innovative training of in-service teachers for active learning: A short teacher development course based on physics education research. Journal of Science Teacher Education, 18, 559-572. http://dx.doi.org/10.1007/s10972-007-9054-7

Table 1. Results of one sample t-test to compare the means of first component in current and desired state

\begin{tabular}{|c|c|c|c|c|c|}
\hline Status & Mean & SD & $t$ & df & Sig. \\
\hline Current status & 2.43 & 0.65 & -8.254 & 87 & 0.00 \\
\hline Desired status & 2.40 & 0.65 & 17.06 & 87 & 0.00 \\
\hline
\end{tabular}

Table 2. Results of one sample t-test to compare the means of second component in current situation and desired

\begin{tabular}{|c|c|c|c|c|c|}
\hline Status & Mean & SD & $t$ & df & Sig. \\
\hline Current Status & 2.95 & 0.62 & -0.74 & 87 & 0.46 \\
\hline Desired Status & 4.26 & 0.46 & 25.25 & 87 & 0.00 \\
\hline
\end{tabular}

Table 3. Results of one sample t-test to compare the means of third component in current and desired state

\begin{tabular}{|c|c|c|c|c|c|}
\hline Status & Mean & SD & $\mathrm{t}$ & $\mathrm{df}$ & Sig. \\
\hline Current Status & 1.84 & 0.85 & -12.76 & 87 & 0.00 \\
\hline Desired Status & 4.29 & 0.69 & 17.47 & 87 & 0.00 \\
\hline
\end{tabular}

Table 4. Results of one sample t-test to compare the means of forth component in current and desired state

\begin{tabular}{|c|c|c|c|c|c|}
\hline Status & Mean & SD & $\mathrm{t}$ & df & Sig. \\
\hline Current Status & 2.58 & 0.77 & -5.15 & 87 & 0.00 \\
\hline Desired Status & 4.38 & 0.52 & 24.87 & 87 & 0.00 \\
\hline
\end{tabular}

Table 5. Results of one sample t-test to compare the means of fifth component current and desired states

\begin{tabular}{|c|c|c|c|c|c|}
\hline Status & Mean & SD & $\mathrm{t}$ & df & Sig. \\
\hline Current Status & 3.27 & 0.78 & 3.25 & 87 & 0.00 \\
\hline Desired Status & 4.52 & 0.47 & 29.80 & 87 & 0.00 \\
\hline
\end{tabular}


Table 6. Results of Paired samples t-test to compare the current and desired state according to study components

\begin{tabular}{|c|c|c|c|c|c|c|c|}
\hline Research Components & Status & Mean & $\mathrm{N}$ & $\mathrm{SD}$ & $\mathrm{t}$ & df & Sig. \\
\hline \multirow[t]{2}{*}{1} & Current & 2.43 & 88 & 0.65 & \multirow{2}{*}{-18.92} & \multirow{2}{*}{87} & \multirow{2}{*}{0.00} \\
\hline & Desired & 4.20 & 88 & 0.66 & & & \\
\hline \multirow[t]{2}{*}{2} & Current & 2.95 & 88 & 0.62 & \multirow{2}{*}{-19.37} & \multirow{2}{*}{87} & \multirow{2}{*}{0.00} \\
\hline & Desired & 4.26 & 88 & 0.46 & & & \\
\hline \multirow[t]{2}{*}{3} & Current & 1.84 & 88 & 0.85 & \multirow{2}{*}{-21.73} & \multirow{2}{*}{87} & \multirow{2}{*}{0.00} \\
\hline & Desired & 4.29 & 88 & 0.69 & & & \\
\hline \multirow[t]{2}{*}{4} & Current & 2.58 & 88 & 0.77 & \multirow{2}{*}{-19.26} & \multirow{2}{*}{87} & \multirow{2}{*}{0.00} \\
\hline & Desired & 4.38 & 88 & 0.52 & & & \\
\hline \multirow{2}{*}{5} & Current & 3.27 & 88 & 0.78 & \multirow{2}{*}{-15.86} & \multirow{2}{*}{87} & \multirow{2}{*}{0.00} \\
\hline & Desired & 4.52 & 88 & 0.47 & & & \\
\hline
\end{tabular}

Table 7. The mean weight of research questions

\begin{tabular}{|c|c|c|c|}
\hline Scale & Mean weight & Status & Question \\
\hline low & 2.43 & current & \multirow{2}{*}{$\begin{array}{l}\text { Control over the content of high school physics } \\
\text { and physics books }\end{array}$} \\
\hline high & 4.20 & desired & \\
\hline medium & 2.95 & current & \multirow{2}{*}{ Teacher professional skills and capabilities } \\
\hline high & 4.26 & desired & \\
\hline low & 1.84 & current & \multirow{2}{*}{ Equipment and Technology Education } \\
\hline high & 4.29 & desired & \\
\hline medium & 2.58 & current & \multirow{2}{*}{ Good books and educational content } \\
\hline high & 4.38 & desired & \\
\hline medium & 3.27 & current & \multirow{2}{*}{ Motivational factors for learning physics lesson } \\
\hline Very high & 4.52 & desired & \\
\hline
\end{tabular}

